\title{
ACUTE DRIVERS AND GREAT BARRIERS FOR SUCCESSFUL BLUE GROWTH IN PAKISTAN: AN INVESTMENT PERSPECTIVE UNDER CPEC
}

\author{
Urooj Aijaz \\ Ph.D Scholar at Jinnah University for Women \\ Faculty Bahria University \\ Karachi - Pakistan \\ uroojaijaz.bukc@bahria.edu.pk \\ Hassan Daud Butt \\ CEO KPK Board of Investment \\ Ph. D Scholar at Bahria University \\ Islamabad - Pakistan \\ hdb4049@gmail.com \\ Dr. Saghir Pervaiz Ghauri \\ Chairperson \\ Department of Economics \\ Jinnah University for Women \\ Karachi-Pakistan \\ Saghir.ghauri@gmail.com
}

* (This paper is the part of dissertation from the PhD thesis of Ms.Urooj Aijaz)

\begin{abstract}
The study aims to determine the drivers and barriers of blue growth success in Pakistan from the CPEC perspective. The study has collected 129 responses from the marine and CPEC officials to gain insightful knowledge and understanding of their opinion based on a seven-point Likert scale questionnaire and purposive-criterion sampling technique. The data analysis was conducted using PLS-SEM for estimating the validity and reliability of the model and hypothesis testing. The results showed that four critical barriers had been identified, including uncertainty avoidance, functional strategic focus, prioritization of the short-term growth (rather than long-term orientation), and weak




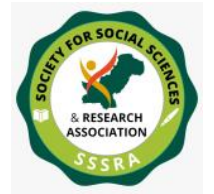

Pak. Journal of Int'L Affairs, Vol 4, Issue 3 (2021)

Acute Drivers and Great Barriers ...

innovativeness. However, the study has also identified that sustainability for businesses, balanced approach between stakeholders and shareholders, and top management commitment/support are major drivers towards blue growth in Pakistan from the CPEC perspective. After conducting the study, it is recommended to policymakers that long-term orientation, the correctness of the strategic focus, and a balanced approach should be mainly emphasized to optimize investment opportunities in CPEC for sustainable blue growth in Pakistan. Moreover, innovativeness should be focus primarily on improving the overall efficiency of CPEC and blue growth in Pakistan in the larger perspective. CPEC is a crucial aspect for blue growth in Pakistan, and therein, a dire need has been highlighted in the literature to undergo the barriers and drivers for blue growth from the CPEC perspective.
\end{abstract}

Keywords: Strategic Focus, Uncertainty, Innovativeness, Top Management Commitment/Support, Blue Growth, CPEC.

\title{
INTRODUCTION
}

Ocean-based economic development has been identified as a renewed interest that can be termed in different ways: blue growth (BG), blue economy, and ocean economy. The term blue growth or economy refers to the enhancement of activities regarding the ocean and marine life. The aspects of blue growth have been accelerating as the importance of oceans is rising, becoming a part of the globalized discourse regarding economic growth (Bennett et al., 2021; Jouffray et al., 2020). The basic concept of blue growth refers to the economic conditions and activities of coasts, seas, and oceans. Also, it effectively covers all interlinked recognized and emerging sectors (Alharthi \& Hanif, 2020). The oceans have been identified as of great importance and value to human society, and it helps develop the blue growth around the globe. The blue growth also develops environmental growth, including different sectors and maritime business (Caswell et al., 2020). Besides, the concept of BG has been rising, especially in the intergovernmental organizations that are European Union and United Nations.

However, there are specific differences or variations in the process through which initiatives of BG are developed and implemented around the world, but it effectively focuses on sustainable development and wellbeing (Bogadóttir, 2020). Various researches have emphasized the importance of BG as it allows to conduct the marine activities in a sustainable way (Van den Burg et al., 2019). Besides, Pakistan has various 


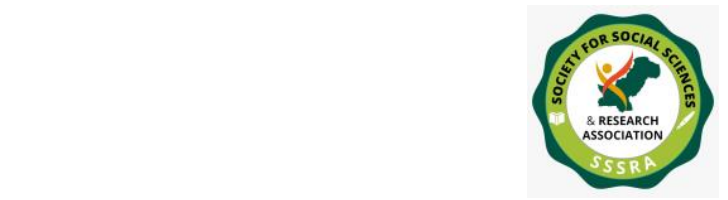

coasts and seas, and its coastline has been around $990 \mathrm{~km}$ to $1046 \mathrm{~km}$ long. Baluchistan alone consists of 730 to $770 \mathrm{~km}$, and it has been identified as a diverse and untapped resource that can be a vital element for the blue economy (Khan, 2020). Similarly, Pakistan contains high natural maritime geography, and it depends on the blue growth for developing its economy. Also, China-Pakistan Economic Corridor (CPEC) has been found to increase the importance of blue growth in the country, but it faces some issues to give the maximum benefits due to security and uncertainty avoidance issues (Askari et al., 2020). However, the country has been largely ambivalent or confused regarding the importance of Sea. It creates sea blindness in the development of the blue growth of Pakistan (Zafar, 2021).

Moreover, some various barriers or problems eventually resulted in the low development of blue growth; for instance, lack of technology, low confidence of investors, in technical and economic aspects of the blue growth. Also, unresolved issues of ownership of different processes regarding the involvement of stakeholders have been identified as another barrier in blue growth. The aspect of prioritizing short-term growth has been another barrier to its growth. Like, high stocks are needed to be developed in blue life but with including the environmental concerns (Buck \& Langan, 2017; Dalton et al., 2019). Similarly, another barrier is the lack of functional strategies that include gaps in maritime knowledge and data, lack of research efforts, lack of geopolitical combined efforts, lack of legislation, and adequate and skilled people. The barriers to innovation have also been identified as a negative factor that could hinder the development of blue growth (SchultzZehden et al., 2019).

Furthermore, another barrier towards the BG is that not a single political party has come forward and included in the policies towards its development, resulting in a long struggle for recognition and development (Zafar, 2021). Although Pakistan has vast resources in this aspect, it has not been possible to gain total success because of reduced maritime success. So, experts have stated that when these blue resources can be utilized properly, they can lead towards effective blue growth in Pakistan (Askari et al., 2020). The lack of cooperation and coordination between value chains, lack of awareness, ineffective information exchange, and lack of access to capital are other barriers to this industry.

The lack of legislation has been identified another barrier towards the use of Sea as a multi-use that can foster the development of multiple approaches and enhance the blue growth (Van den Burg et al., 2019). Besides, blue growth can be used for environmental effects as it can help reduce climate change and develop the blue growth sector. However, economic, social, and political barriers are a significant hindrance in reducing the environmental degradation caused by different $\mathrm{CO}^{2}$ emissions in these processes 


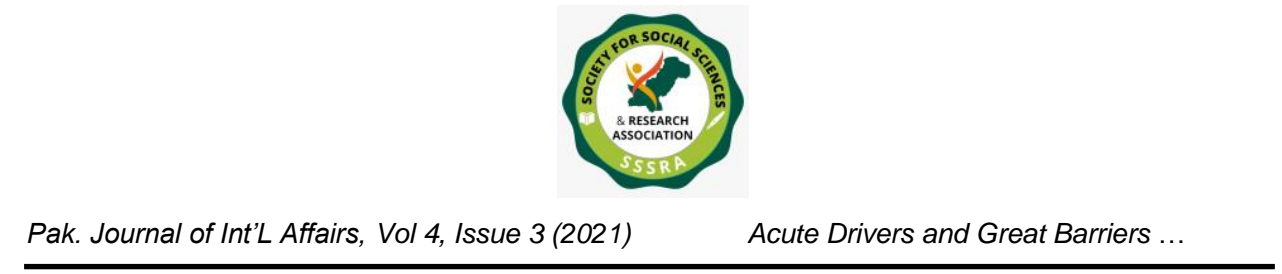

(Froehlich et al., 2019). Hence, based on the identified problems and issues of blue growth, this research has raised a question to determine the drivers and barriers of blue growth success in Pakistan from the CPEC perspective.

Practical implementation and its drivers of blue growth are lacking in the literature as a consolidated framework for this process are not yet developed. So, this research can help the researcher provide practical knowledge based on the current and innovative framework. A few researchers have found a gap regarding this that could hinder the integration of blue growth within the oceans (Sadiq et al., 2021). Similarly, another gap in this topic is the lack of awareness regarding maritime activities, as prior research has not provided practical knowledge to fill this gap (Schultz-Zehden et al., 2019). Also, the lack of effective strategies is limited in the literature, and fulfilling this gap can help policymakers further understand the importance of blue growth (Brugère et al., 2019). Additionally, CPEC is a crucial aspect for blue growth in Pakistan, and therein, a dire need has been highlighted in the literature to undergo the barriers and drivers for blue growth from the CPEC perspective. The paper follows the literature review, methodology, results, and implications of the study while also providing keen and vital future research directions.

\section{LITERATURE REVIEW}

\section{Potential Barriers to Blue Growth}

The concept of blue growth has been rising around the globe as it can develop the oceans' life and decrease environmental degradation. However, specific barriers hinder this process and the development of blue growth as a whole (Van den Burg et al., 2019). Like, uncertainty avoidance has been a significant barrier in this process as it refers to the concept that the people are aware of regarding the lack of blue growth but considers it acceptable anyhow. This construct is related to Hofstede's cultural dimension theory which states the role of culture on different activities (Guijarro-García et al., 2020). Uncertainty avoidance has been identified as a significant factor in being a barrier to blue growth. The development of blue growth has been termed highly uncertain in different oceans and Seas as when the rules and principles are not well defined, it can lead to industry degradation (Schultz-Zehden et al., 2019).

Furthermore, functional strategy (FS) has been identified as another barrier to blue growth that can hinder its growth. The basic concept of FS can be identified as practical strategies that are not being implemented, resulting in low blue growth due to ineffective planning (Kyvelou \& Ierapetritis, 2019). Also, as the practical strategies might be 


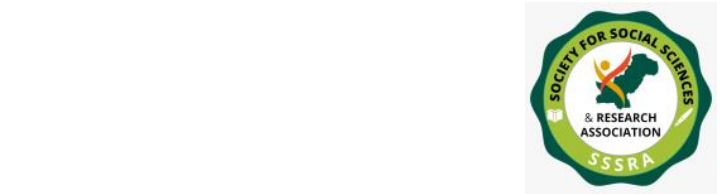

effective towards building the blue growth, it is necessary to examine and reflect their actual meanings and what these strategies entail in this industry. The strategies can also identify the further possibility of development in BG (Leposa, 2020). However, the fundamental strategic aspect and its intentions do not directly influence the actual blue growth, and there is a certain lack of practical strategies in the planning processes. Similarly, it has been identified that different regional strategies are lacking concrete ideas and are not broad for supporting the blue growth. Sustainable development in BG has been identified as a most significant challenge in which the strategies are not implemented adequately towards its effectiveness (Katila et al., 2019).

The prioritizing of short-term growth has been identified as one of the significant barriers to blue growth as it focuses on developing a high number of products without considering its long-term effect on blue growth (Brent et al., 2020). According to Schultz-Zehden et al. (2019), this production must not be included in marine life as it might help gain socioeconomic gains but can cause a negative influence on nature and people as well. Additionally, weak innovativeness can be termed a strategic failure in which there are no new ideas or collaborative working to solve environmental problems (Schultz-Zehden et al., 2019). The role of innovation can be a significant factor in blue growth as it can reinvent the processes based on new ideas and technologies. Its concept is based on adequate strategies, solutions, and ideas for the betterment of environmental and social problems with the collaboration of different actors. The success of this process depends on pure collaboration and trust between different actors or stakeholders (Eikeset et al., 2018). A theoretical linkage can further develop this factor lack of innovativeness with disruptive innovation theory in which it focuses on design-driven innovation in the blue ocean strategies. For instance, new values can be created based on the shared value concept based on a value regeneration strategy. The aspects above have shown a high need for innovation in the services and products for creating a competitive edge for blue growth (KOCA \& SAĞSAN, 2020). Hence, based on the above discussions this study has hypothesized that:

Hla: Uncertainty avoidance has a significant effect on blue growth.

H1b: Functional strategy has a significant effect on blue growth.

H1c: Prioritizing short-term growth has a significant effect on blue growth.

H1d: Weak innovativeness has a significant effect on blue growth.

\section{Potential Drivers of Blue Growth}

Furthermore, specific drivers can develop the blue growth and its development as well. Like, they value business sustainability has been termed a significant driver as it focuses 


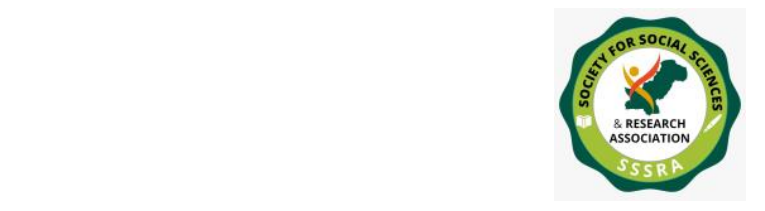

Acute Drivers and Great Barriers ...

on creating a sustainable business and providing practical value. The presence of a sustainable business can significantly influence the effective development of blue growth. For instance, when the production processes are promoted as efficient, clean, and controlled, it brings environmental sustainability (Bogadóttir, 2020). Besides, the business model should be sustainable, and its related business plans can help develop an influential milestone for blue growth.

Similarly, for this process, environmental concerns are highlighted since the beginning as they can create sustainability in business for the proposed system or industry (Lagasco et al., 2019). Also, business sustainability has termed a demand for production but with high quality, certifications, and innovative techniques to better the industry and environment (Saviolidis et al., 2020). In this study, the researcher has taken business sustainability for valuing business sustainability.

Moreover, a balanced approach has been identified as another driver for blue growth as it refers towards having a balance between costs and benefits of the production for sustainable production in the blue growth. Similarly, when the production processes are balanced with the environmental sustainability as well as with the benefits, then helps policymakers interacting with better policies creation (Klinger et al., 2018). The blue growth also focuses on prioritizing the balanced approach to balance sustainable and socioeconomic management of the natural resources. Efficient use of aquaculture, livelihoods, food systems, trade, and ecosystem services can significantly influence blue growth (FAO, 2015). The core of this process is to identify and recognize the dynamic balance between resources and the environment. These aspects can be helpful towards integrating a balanced approach of growth and sustainability of the environment (Wenhai et al., 2019).

Additionally, top management support or commitment has been identified as another driver for blue growth as it focuses on practical management or support for the benefits of aquaculture activities and eventually the blue growth (Van den Burg et al., 2019). The top management can significantly influence the blue growth by conducting proper actions towards minimizing the presence of any barriers and countering it. Similarly, blue growth can be developed through a holistic management approach regarding marine life and its social-ecological systems (Kyvelou \& Ierapetritis, 2019). Also, the betterment of blue growth and its economy can help the people as it can provide practical resources through effective management, support, and innovation (Bethel et al., 2021). In addition, enabling innovation structure has been termed another driver for blue growth as it focuses on integrating strategic vision within the Sea to develop innovative techniques for better growth. The presence of innovation has been identified as an essential factor for the 
development of blue growth as it can engage in its growth with sustainability (Recalde, 2019). The blue growth can be developed innovatively by identifying innovative specialization concepts that include efficient resource use, greener resources, a competitive economy, and high employment that provide socio-territorial cohesion (Schultz-Zehden et al., 2019). In this study, the researcher has taken enabling innovation structure as innovation. Hence, based on the above discussions this study has hypothesized that:

H2a: Valuing business sustainability has a significant effect on blue growth. $H 2 b$ : Balanced approach has a significant effect on blue growth.

H2c: Top management support/commitment has a significant effect on blue growth.

H2d: Enabling innovation structure has a significant effect on blue growth.

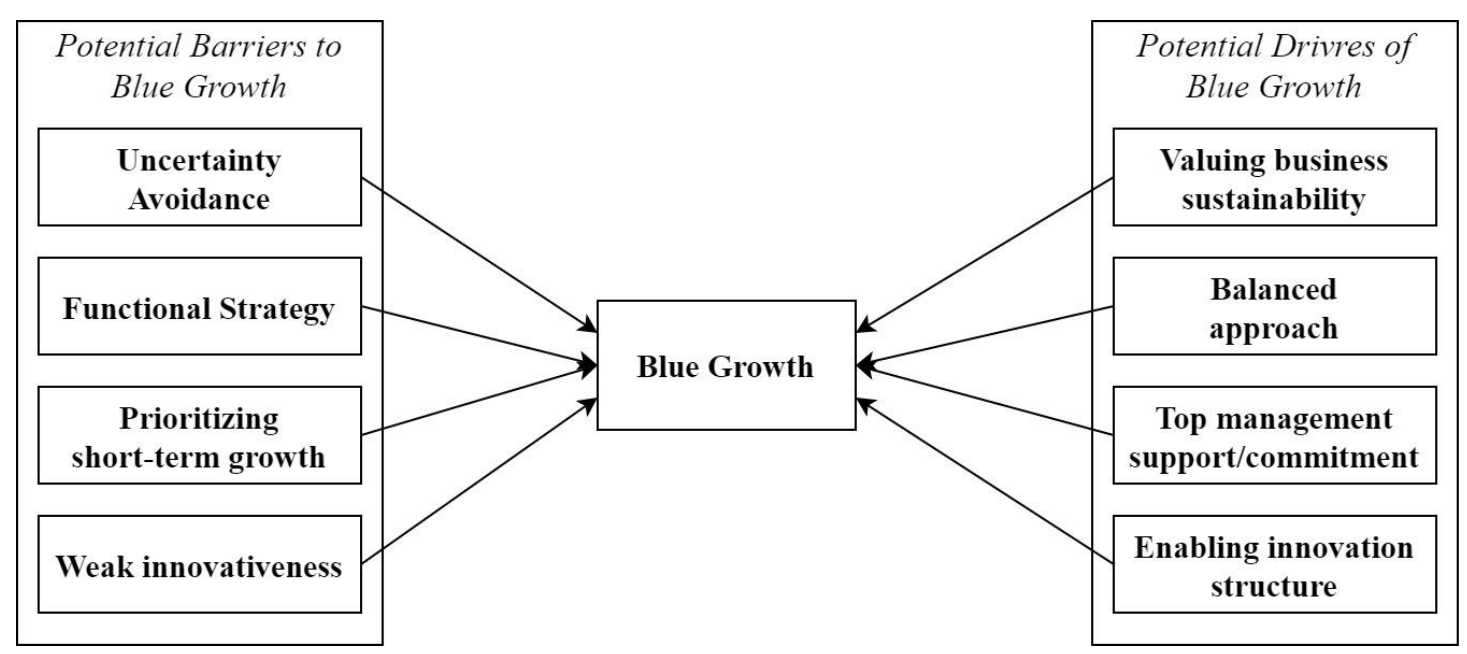

Figure 1: Research Framework

\section{METHODOLOGY}

\section{Research design}

The quantitative-deductive approach has enabled the study to test the hypothesis based on theoretical underpinnings explaining the barriers and drivers of blue growth in Pakistan (Creswell \& Creswell, 2017). In the same line, the study has used a positivistic philosophical approach to extend the knowledge about blue growth in Pakistan in the natural environment based on individuals' opinions, knowledge, and experience (Newman \& Benz, 1998). Further, the study has enabled the theoretical and practical 
findings to enrich practitioners, theorists, and academicians about the blue economy and growth in Pakistan (Scott \& Garner, 2013); therefore, the study was based on a nonexperimental causal design.

\section{Sampling design}

The study has collected data at a single point of time, and so a cross-sectional time horizon has been used (Sekaran \& Bougie, 2010) while the responses were collected from the marine and CPEC officials of Pakistan; therefore, individuals were the unit of analysis in the study (Sekaran \& Bougie, 2016). Conversely, the study has used the N10 formula for estimating minimum responses from the sample population, wherein $N$ refers to the number of constructs in the model (Hair et al., 2011). Therein, 129 responses have been collected for data analysis using a structured five-point Likert scale instrument. Lastly, the study has collected responses from the predetermined units of the sample population; however, the size of the sample population was unknown (Cochran, 2007; Vehovar et al., 2016) and, therefore, nonprobability purposive- criterion sampling technique has been used.

The following table 1 provides the demographic profile of the respondents.

\section{Table 1:}

Profile of the Respondents ( $\mathrm{n}=129)$

\begin{tabular}{llcc}
\hline \multirow{2}{*}{ Gender } & Male & Frequency & Percent \\
& Female & 68 & 52.7 \\
& 30 and Under & 61 & 47.3 \\
Age Group & $31-40$ Years & 32 & 24.8 \\
& 41 - 50 Years & 30 & 23.3 \\
& 51 and Above Years & 33 & 26.4 \\
Sector Type & Public & 68 & 25.6 \\
& Private & 61 & 52.7 \\
& Less than 3 Years & 27 & 47.3 \\
& $3-5$ Years & 17 & 20.9 \\
Experience & 6-8 Years & 25 & 13.2 \\
& $9-11$ Years & 27 & 19.4 \\
& 11 and More & 33 & 20.9 \\
& & & 25.6 \\
\hline
\end{tabular}




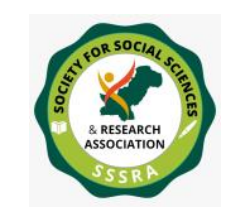

Pak. Journal of Int'L Affairs, Vol 4, Issue 3 (2021)

Acute Drivers and Great Barriers ...

\section{Instrument}

There are 9 variables in this research. The uncertainty avoidance has been based on 4 items adopted from Jung and Kellaris (2004). Like, "Blue growth economy does not like ambiguous situations". The functional strategy has been based on 5 items adopted from Ramakrishnan (2010). For instance, "Competitors prices are not being monitored by blue growth firms". The prioritizing short-term growth has been based on 7 items adopted from Grinyer et al. (1998); Marston and Craven (1998); Segelod (2000). For example, "Due to internal factors it is easier to prioritize short-term blue growth". The weak innovativeness has been based on 8 items adopted from Muñoz-van den Eynde et al. (2015). Like, "Blue growth does not focus on creativity, having new ideas". The valuing business sustainability has been based on 5 items adopted from Chow and Chen (2012). For instance, "Blue growth firm reduced wastes and emissions from operations". The balanced approach has been based on 4 items adopted from Malbašić et al. (2015). For example, "The development values in blue growth aimed at differentiating and continuously improving the company (e.g., innovation, creativity, learning, and continuous improvement)". The top management support/commitment has been based on 6 items adopted from Chu et al. (2017). For example, "Top managers recognize the importance of blue growth practices". The enabling innovation structure has been based on 5 items adopted from Y1ldiz et al. (2014). For instance, "Our process in blue growth often implements fresh ideas". The blue growth has been based on 7 items adopted from Saviolidis et al. (2020). Like, "The industry has developed during last few years".

\section{Data analysis}

Among the $2^{\text {nd }}$ generation statistical techniques, there is a widespread scholarly discussion on the use of CB-SEM and PLS-SEM (Hair et al., 2016). However, numerous researchers have explicitly discussed the applicability of PLS-SEM with specific criteria (Hair et al., 2019). For instance, Hair et al. (2011) suggested that PLS-SEM applies to causal studies, and therein, the study has a causal design. Further, Hair et al. (2013) recommended that PLS-SEM can apply to studies with a small sample size $(\mathrm{n}<250)$, and therein, the study has collected 129 responses from the sample population. In addition, the study has an exploratory model; therefore, Hair et al. (2017) suggested that exploratory studies lead to theory development and therein, predictive-orientation has been focused in the current study.

\section{RESULTS}




\section{Measurement model}

PLS-SEM analysis has the initial estimation of measurement model that refers to the examining the relationship between indicators and constructs that are related with each other in the theoretical perspective. This analysis provides keen validation and reliability of the indicators and constructs based on factor loadings and their statistical significance, reliability estimations such as Cronbach's alpha, and composite reliability (CR) and the inter-correlation between indicators to present their latent construct in the model based on average variance extracted (AVE). The following table 2 provides the result of measurement model comprehensively. 
Table 2:

Measurement Model using PLS Algorithm

\begin{tabular}{|c|c|c|c|c|c|c|}
\hline Latent Constructs & Indicators & Loadings & Prob. & Alpha & CR & AVE \\
\hline \multirow{4}{*}{ Balanced Approach } & BA1 & 0.910 & 0.000 & \multirow{4}{*}{0.810} & \multirow{4}{*}{0.876} & \multirow{4}{*}{0.640} \\
\hline & $\mathrm{BA} 2$ & 0.780 & 0.000 & & & \\
\hline & $\mathrm{BA} 3$ & 0.776 & 0.000 & & & \\
\hline & $\mathrm{BA} 4$ & 0.721 & 0.000 & & & \\
\hline \multirow{6}{*}{ Blue Growth } & $\mathrm{BG} 2$ & 0.749 & 0.000 & \multirow{6}{*}{0.885} & \multirow{6}{*}{0.915} & \multirow{6}{*}{0.648} \\
\hline & BG3 & 0.923 & 0.000 & & & \\
\hline & BG4 & 0.930 & 0.000 & & & \\
\hline & BG5 & 0.891 & 0.000 & & & \\
\hline & BG6 & 0.741 & 0.000 & & & \\
\hline & BG7 & 0.521 & 0.000 & & & \\
\hline \multirow{4}{*}{$\begin{array}{l}\text { Enabling Innovation } \\
\text { Structure }\end{array}$} & EIS1 & 0.972 & 0.000 & \multirow{4}{*}{0.924} & \multirow{4}{*}{0.945} & \multirow{4}{*}{0.813} \\
\hline & EIS3 & 0.901 & 0.000 & & & \\
\hline & EIS4 & 0.823 & 0.000 & & & \\
\hline & EIS5 & 0.904 & 0.000 & & & \\
\hline \multirow{4}{*}{ Functional Strategy } & $\mathrm{FS} 2$ & 0.744 & 0.000 & \multirow{4}{*}{0.893} & \multirow{4}{*}{0.918} & \multirow{4}{*}{0.738} \\
\hline & FS3 & 0.943 & 0.000 & & & \\
\hline & FS4 & 0.882 & 0.000 & & & \\
\hline & FS5 & 0.856 & 0.000 & & & \\
\hline \multirow{3}{*}{$\begin{array}{l}\text { Prioritizing Short-Term } \\
\text { Growth }\end{array}$} & PSTG3 & 0.937 & 0.000 & \multirow{3}{*}{0.875} & \multirow{3}{*}{0.923} & \multirow{3}{*}{0.802} \\
\hline & PSTG4 & 0.935 & 0.000 & & & \\
\hline & PSTG5 & 0.808 & 0.000 & & & \\
\hline \multirow{5}{*}{$\begin{array}{l}\text { Top Management } \\
\text { Support/Commitment }\end{array}$} & TMSC1 & 0.758 & 0.000 & \multirow{5}{*}{0.911} & \multirow{5}{*}{0.934} & \multirow{5}{*}{0.738} \\
\hline & TMSC2 & 0.839 & 0.000 & & & \\
\hline & TMSC4 & 0.915 & 0.000 & & & \\
\hline & TMSC5 & 0.914 & 0.000 & & & \\
\hline & TMSC6 & 0.861 & 0.000 & & & \\
\hline \multirow{4}{*}{ Uncertainty Avoidance } & UA1 & 0.985 & 0.000 & \multirow{4}{*}{0.973} & \multirow{4}{*}{0.979} & \\
\hline & $\mathrm{UA} 2$ & 0.912 & 0.000 & & & 0021 \\
\hline & UA3 & 0.983 & 0.000 & & & 0.921 \\
\hline & UA4 & 0.956 & 0.000 & & & \\
\hline & VBS1 & 0.918 & 0.000 & & & \\
\hline $\begin{array}{l}\text { aluing Business } \\
\text { Sustainability }\end{array}$ & VBS2 & 0.958 & 0.000 & 0.941 & 0.962 & 0.893 \\
\hline & VBS3 & 0.959 & 0.000 & & & \\
\hline & WI1 & 0.832 & 0.000 & & & \\
\hline Weak Innovativeness & WI2 & 0.914 & 0.000 & 0891 & 0924 & 0752 \\
\hline & WI3 & 0.863 & 0.000 & 0.891 & 0.924 & 0.752 \\
\hline & WI7 & 0.858 & 0.000 & & & \\
\hline
\end{tabular}




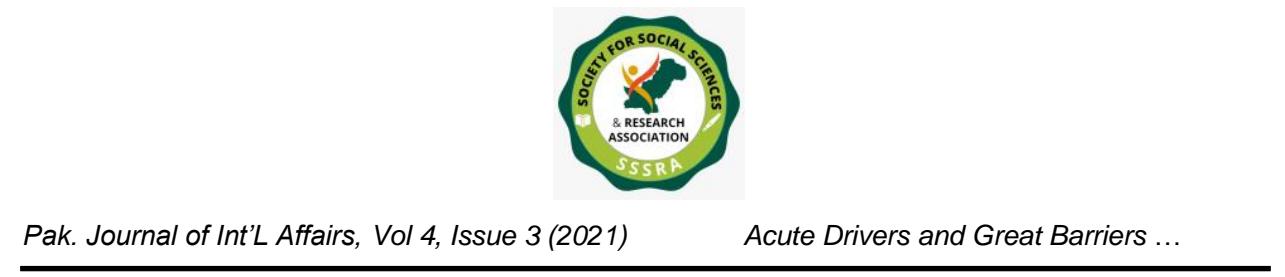

Table 2 provided that indicators have reliability higher than the recommended cut-off values of 0.50 (Hair et al., 2016) and found statistically significant at 5 percent level. Therefore, indicators have contributed substantially for appropriate construct development. Furthermore, latent constructs have achieved higher degree of internal consistency and convergence based on Cronbach's alpha, CR and AVE respectively. The acceptable cut-off value of alpha was 0.70 (Nunnally \& Bernstein, 1994), construct should be considered substantially consistency in case of CR higher than 0.80 (Hair et al., 2011; Hair et al., 2019) and AVE higher than 0.50 represents substantial degree of convergence between indicators and constructs (Hair et al., 2017; Hair et al., 2016; Hair et al., 2011). Herein, constructs have achieved convergent validity based on alpha, CR and AVE.

\section{Discriminant validity}

The discriminant validity focuses on identifying the discriminant between variables. Like, it represents that the items of each construct highly supports their own constructs only as compared with other constructs (Hair et al., 2016). The HTMT ratio has been termed as a new approach for examining the validity in variance-based SEM. This test focuses on assessing the correlations in indicators within the same construct. HTMT has been termed as a relatively more advanced test for assessing the discriminant as it builds on the measures and data that are available and does not required calculation of construct scores (Henseler et al., 2015). In this regards, following table 3 shows that all constructs have HTMT ratio less than the recommended cut-off value of 0.90 (Henseler et al., 2015). The highest value is 0.890 and therefore, discriminant validity had been achieved using HTMT ratio. 


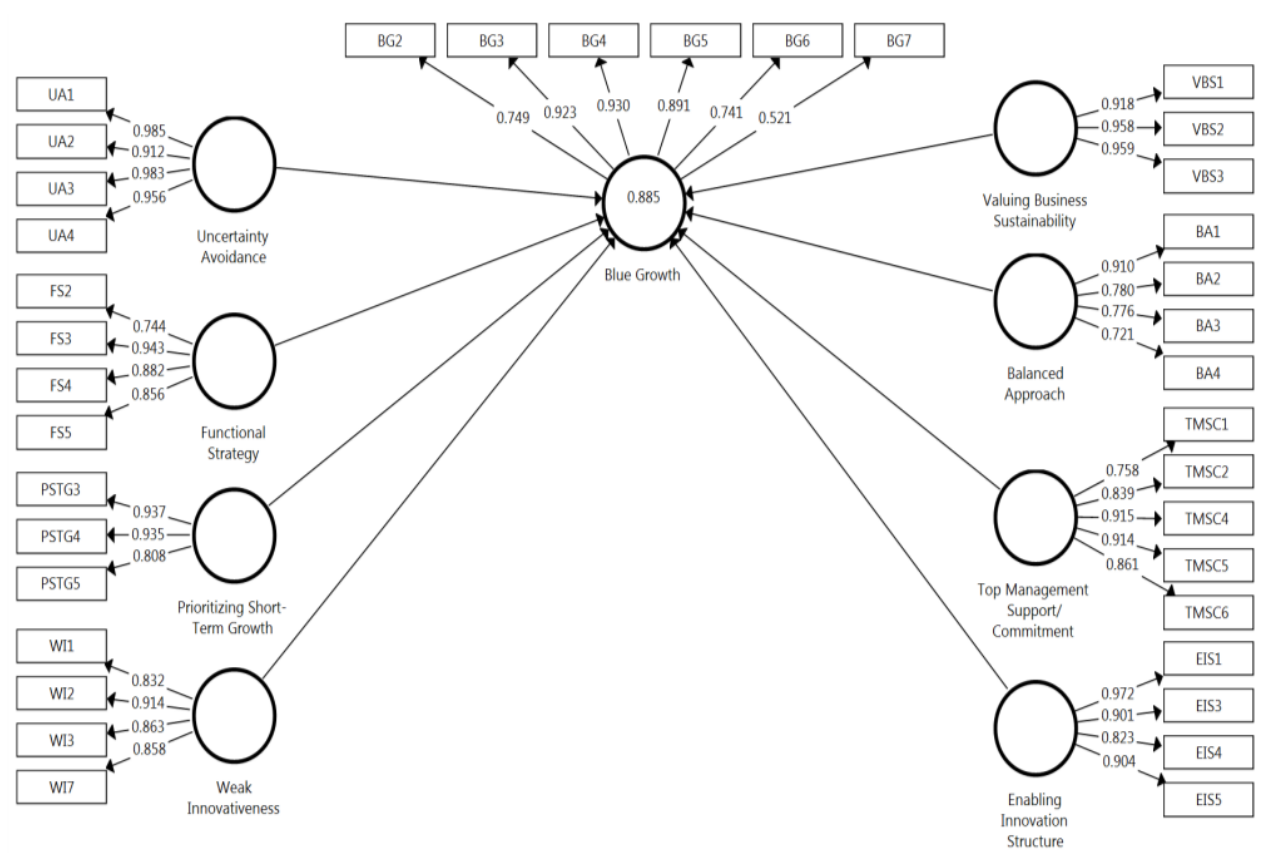

Figure 2: PLS Algorithm using Smart PLS v3.2.9

Table 3:

Discriminant Validity using HTMT Ratio

$\begin{array}{lllllllll}\text { BA } & \text { BG } & \text { EIS } & \text { FS } & \text { PSTG } & \text { TMSC } & \text { UA } & \text { VBS } & \text { WI }\end{array}$

Balanced Approach

Blue Growth

Enabling Innovation Structure

Functional Strategy

Prioritizing Short-Term Growth

Top Management

Support/Commitment

Uncertainty Avoidance

Valuing Business Sustainability

Weak Innovativeness

$B A=$ Balanced Approach; $B G=$ Blue Growth; $E I S=$ Enabling Innovation Structure; $F S=$ Functional Strategy; $P S T G=$ Prioritizing ShortTerm Growth; TMSC = Top Management Support Commitment; $U A=$ Uncertainty Avoidance; VBS $=$ Valuing Business Sustainability; $W I=$ Weak Innovativeness
0.872

$0.453 \quad 0.589$

$\begin{array}{lll}0.513 & 0.621 & 0.800\end{array}$

$\begin{array}{llll}0.500 & 0.778 & 0.438 & 0.522\end{array}$

$\begin{array}{lllll}0.774 & 0.848 & 0.759 & 0.688 & 0.890\end{array}$

$\begin{array}{llllll}0.220 & 0.309 & 0.328 & 0.864 & 0.244 & 0.239\end{array}$

$\begin{array}{lllllll}0.603 & 0.723 & 0.885 & 0.780 & 0.376 & 0.797 & 0.334\end{array}$

$\begin{array}{llllllll}0.713 & 0.856 & 0.66 & 0.668 & 0.741 & 0.774 & 0.379 & 0.573\end{array}$




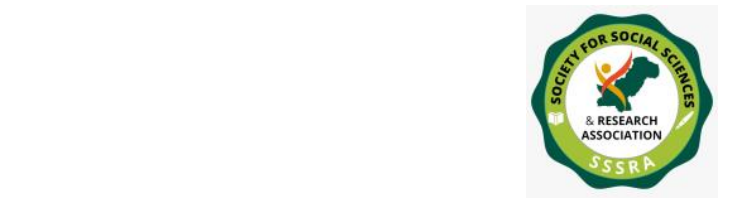

Pak. Journal of Int'L Affairs, Vol 4, Issue 3 (2021)

Acute Drivers and Great Barriers ...

\section{Structural model}

The structural model also known as an inner model used for hypothesis-testing to generate main results of the research. The objectivity of the structural model is to examine the hypothesized relationship between latent constructs in the model framework. The results in table 4 showed that uncertainty avoidance $(\beta=-0.331, p<0.05)$ has a negatively significant effect on blue growth. Functional strategy $(\beta=-0.764, p<0.01)$ has a negatively significant effect on blue growth. Prioritizing short-term growth $(\beta=-$ $0.591, \mathrm{p}<0.01$ ) has a negatively significant effect on blue growth. Weak innovativeness $(\beta=-0.274, p<0.01)$ has a negatively significant effect on blue growth. These results showed that functional strategy is one of the key barriers of blue growth in Pakistan followed by management myopic perspective of short-termism while least importantly, weak innovativeness found as a weak barrier to blue growth in Pakistan. Furthermore, valuing business sustainability $(\beta=0.724, p<0.01$ ) has a positively significant effect on blue growth. Balanced approach $(\beta=0.420, \mathrm{p}<0.01)$ has a positively significant effect on blue growth. Top management support/commitment $(\beta=0.260, \mathrm{p}<0.01)$ has a positively significant effect on blue growth. However, enabling innovation $(\beta=0.060, p$ $>0.05$ ) has no effect on blue growth. This provided that valuing business sustainability is one of the key drivers of blue growth in Pakistan followed by balanced approach between stakeholders and shareholders and least importantly, top management commitment and support towards blue growth in Pakistan. Lastly, blue growth has been predicted up to 88.5 percent in the modeling framework based on PLS algorithm estimations while its cross-redundancy validation has been found as 55.8 percent that is higher than zero (Hair et al., 2016); based on Geisser (1975); Stone (1974) technique. 


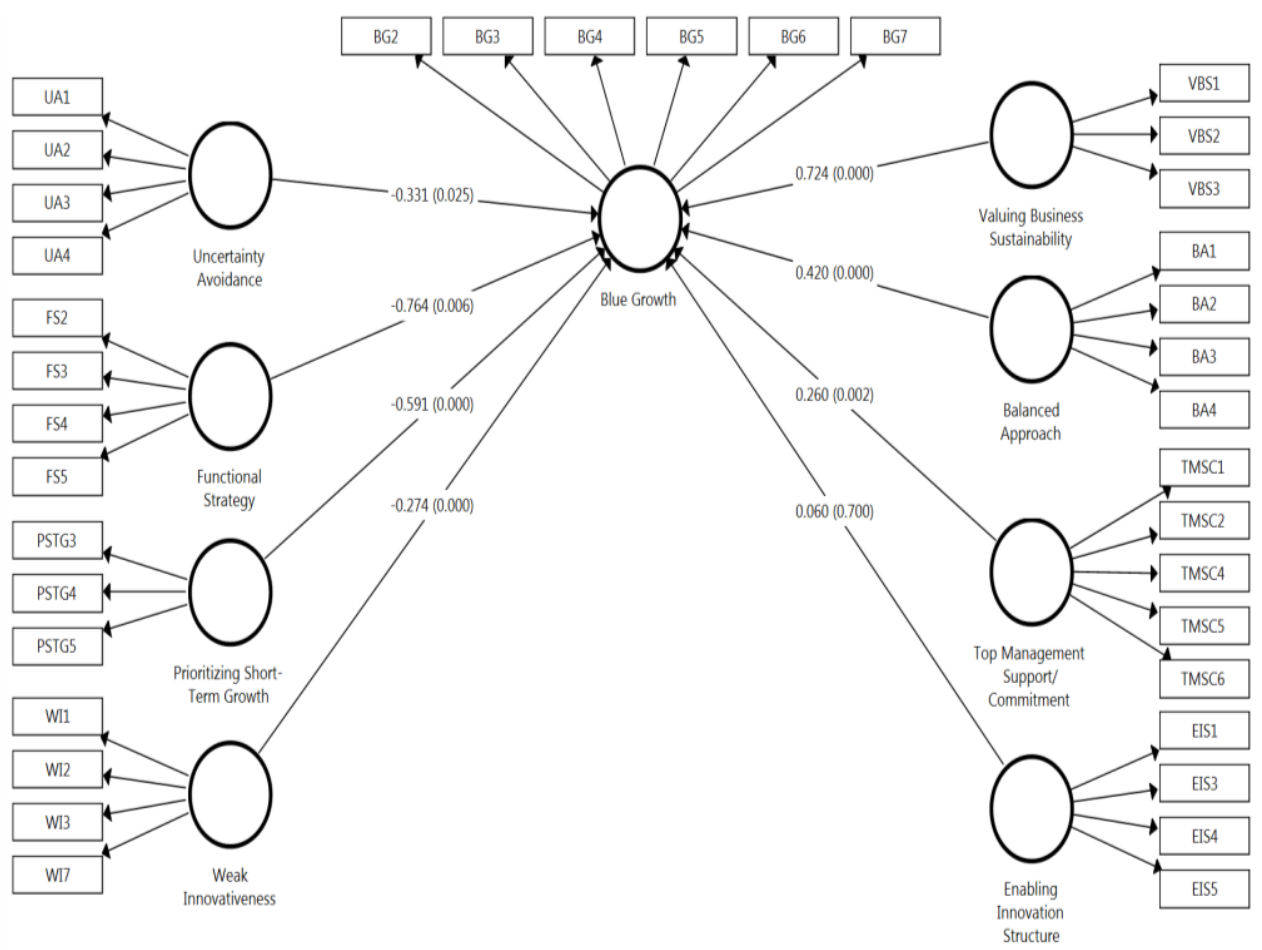

Figure 3: PLS Bootstrapping using Smart PLS v3.2.9

Table 3:

Hypothesis-testing using PLS path modeling

Path Relationships

Estimate T-Stats Prob. Decision

Potential Barriers

H1a: Uncertainty Avoidance $>$ Blue Growth

$\begin{array}{llll}-0.331 & 2.236 & 0.025 & \text { Accepted }\end{array}$

$\mathrm{H} 1 \mathrm{~b}$ : Functional Strategy $>>$ Blue Growth

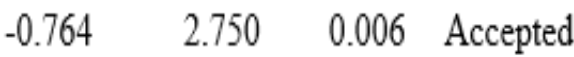

H1c: Prioritizing Short-Term Growth $>>$ Blue Growth

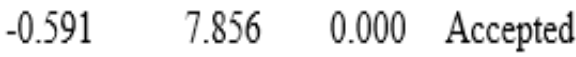

H1d: Weak Innovativeness $>$ Blue Growth

$\begin{array}{lll}-0.274 & 4.147 \quad 0.000 \quad \text { Accepted }\end{array}$

\section{Potential Drivers}

H2a: Valuing Business Sustainability $>$ Blue Growth

$0.724 \quad 6.143 \quad 0.000$ Accepted

$\mathrm{H} 2 \mathrm{~b}$ : Balanced Approach $>>$ Blue Growth

$0.420 \quad 5.415 \quad 0.000 \quad$ Accepted

H2c: Top Management Support/Commitment >> Blue Growth

$0.260 \quad 3.084$

0.002 Accepted

$\mathrm{H} 2 \mathrm{~d}$ : Enabling Innovation Structure $>>$ Blue Growth

$\begin{array}{llll}0.060 & 0.385 & 0.700 & \text { Rejected }\end{array}$

Predictive Relevance of Blue Growth: $R$-Square $=0.885 ;$ Q-Square $=0.558$

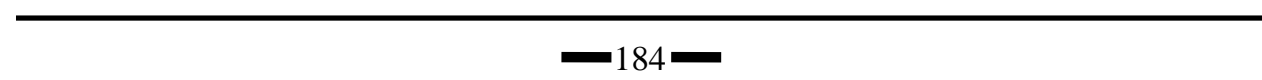




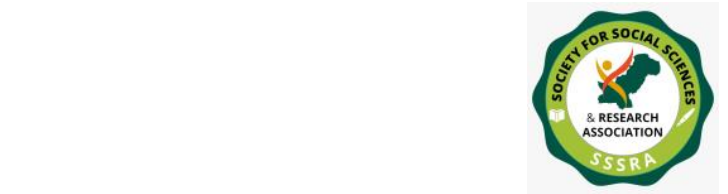

Pak. Journal of Int'L Affairs, Vol 4, Issue 3 (2021)

Acute Drivers and Great Barriers ...

\section{Discussions}

As far as potential barriers to blue growth are concerned, the present study found a that there is a significant relationship between uncertainty avoidance and blue growth which is also supported by Kamalia (2020). However, in contrast with the current findings a study found an insignificant relationship between uncertainty avoidance and blue growth Schultz-Zehden et al. (2019). Furthermore, the study also identified a significant influence of functional strategy on blue growth. This finding is also supported by Wenhai et al. (2019). In contrast with the study's findings an insignificant effect of functional strategy on blue growth Eikeset et al. (2018). Moreover, the study found that there is a negative and significant relationship between prioritizing short term growth and blue growth which is also consistent with Hussain et al. (2017). However, in contrast to the current findings a study found that there is an insignificant relationship between prioritizing short term growth and blue growth Daly et al. (2021). Similarly, the study found that there is a significant relationship between weak innovativeness and blue growth. This result is also in line with Hossain et al. (2020) . Besides, another study found that there is an insignificant relationship between weak innovativeness and blue growth Pauli (2010).

Furthermore, when it comes to potential drivers to blue growth, the current study found a significant influence of valuing business strategy on blue growth. This outcome is also in line with Humayun and Zafar (2014). Moreover, another study found an insignificant influence of valuing business strategy on blue growth Reinertsen and Asdal (2019). Besides, the study found a significant influence of balanced approach on blue growth which is also supported by Lin and Cheng (2020). Also, another study found an insignificant influence of balanced approach on blue growth Lopes et al. (2019). Similarly, the study indicates that there is a significant influence of top management support/commitment on blue growth which is also supported by Kyvelou and Ierapetritis (2019). Also, a contrasting result indicates that there is an insignificant influence of top management support/commitment on blue growth Mayén Cañavate et al. (2019). Additionally, the study identified that there is an insignificant effect of enabling innovation structure on blue growth. This result is also supported by Saviolidis et al. (2020) that when the management does not properly develop innovation structure than it cannot help to enhance their blue growth. Lastly, a contrasting result identified that there is an insignificant effect of enabling innovation structure on blue growth Barbesgaard (2018).

\section{IMPLICATIONS AND FUTURE RESEARCH}




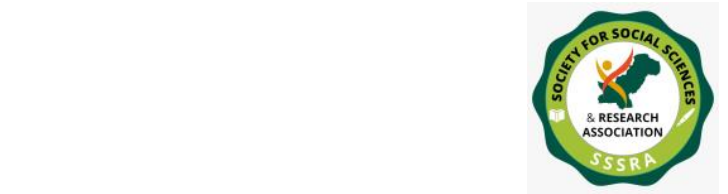

Pak. Journal of Int'L Affairs, Vol 4, Issue 3 (2021)

Acute Drivers and Great Barriers ...

\section{Implications}

Policymakers are suggested to develop strategies that may allow the country to understand Uncertainty Avoidance better to reduce it as much as possible. By doing so, they may simulate uncertainty avoidance that may allow overcoming this barrier for blue growth to take place more efficiently. Additionally, to reduce risk and uncertainty while increasing efficiency, policymakers should develop and implement policies that encourage industries to assess risk mitigation and maximize the use of functional capabilities by establishing clear functional boundaries and defining the three vital functionalities, which are functional responsibility, functional accountability, and functional authority all of which are essential for blue growth.

Policymakers are suggested to develop policies that will make industries resource their respective companies. By implementing such policies, it may encourage organizations to focus on long-term growth instead of short-term growth. Moreover, policymakers are suggested to reassess the resource return policies. The resource usage period may be extended that may encourage companies to focus on long-term growth. Finally, policymakers should emphasize standard procedures mandatory in their policies for industries. As a result of which, organizations shift their focus towards standard procedures while also neglecting the need for innovation that are relatively tend to be weak and act as a significant obstacle for the blue growth to take place.

Policymakers should develop and implement policies that encourage the use of ecofriendly procedures by industries in order for them to make a good reputation socially, maintain themselves as environmentally friendly and maintain a competitive edge economically, all of which hold positive value for any organization to improve their longterm business viability. Furthermore, Policymakers are suggested to implement a policy that makes organizations carry out their operations while also reducing the potentially hazardous impacts on the environment, both of which are mandatory. By implementing such policy, organizations will seek alternative methods to produce their goods that reduce any pollution generated, which as a consequence improve blue growth.

Policymakers are suggested to implement mandatory policies for top management to facilitate employee authorization and value-added stages of job satisfaction through its leadership and commitment to total quality management. Providing necessary tools to employees should also be added as a mandatory procedure in the policy as well. Another policy should be added that reserves all rights of employee wellbeing on account of top management. Furthermore, policymakers are advised to implement a policy that 


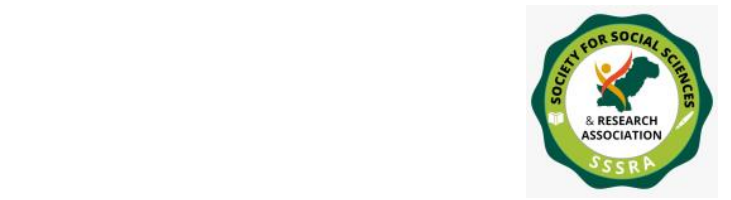

encourages industries to overcome bureaucratic issues and a lack of cross-functional collaboration, resulting in innovation structures that can occur and be funded.

\section{Limitations and future research}

Indeed, there are some limitations and boundaries of the study, like other researches. For instance, the study has used a quantitative-deductive approach to understand and explain the barriers and drivers of blue growth in Pakistan. However, future studies should explain the determinants of blue growth in other developing countries like Bangladesh, Nepal, and the Maldives. Furthermore, the study has collected data from the marine and CPEC officials linked with Pakistan's blue economy perspective. However, government officials, ministry personnel, and NGO officials were not considered to specify the research horizon. In this line, the study has recommended to future research that government perspective and external stakeholders like importers can be considered to enrich the understanding of blue economy growth and development in the broader perspective. In addition, the study has collected 129 responses due to lack of accessibility to respondents and large-scale data collection during the COVID-19 pandemic. However, it is recommended that future studies increase the responses to gain more insightful knowledge and information about the blue economy growth. Lastly, the study has used the PLS-SEM technique for data analysis with some statistical limitations like lack of considerations to data distribution assumptions and theory development rather than theory confirmation; therefore, future studies should estimate the findings based on CBSEM theory confirmation and confirmatory factor analysis (CFA). 


\section{References}

Alharthi, M., \& Hanif, I. (2020). Impact of blue economy factors on economic growth in the SAARC countries. Maritime Business Review.

Askari, M. U., Tahir, M., \& Shaheen, N. (2020). Blue Economy of Pakistan: Challenges and Prospects. Journal of the Punjab niversity Historical Society, 33(02).

Barbesgaard, M. (2018). Blue growth: savior or ocean grabbing? The Journal of Peasant Studies, 45(1), 130-149.

Bennett, N. J., Blythe, J., White, C. S., \& Campero, C. (2021). Blue growth and blue justice: Ten risks and solutions for the ocean economy. Marine Policy, 125, 104387.

Bethel, B. J., Buravleva, Y., \& Tang, D. (2021). Blue Economy and Blue Activities: Opportunities, Challenges, and Recommendations for The Bahamas. Water, 13(10), 1399.

Bogadóttir, R. (2020). Blue Growth and its discontents in the Faroe Islands: an island perspective on Blue (De) Growth, sustainability, and environmental justice. Sustainability Science, 15(1), 103-115.

Brent, Z. W., Barbesgaard, M., \& Pedersen, C. (2020). The Blue Fix: What's driving blue growth? Sustainability Science, 15(1), 31-43.

Brugère, C., Aguilar-Manjarrez, J., Beveridge, M. C., \& Soto, D. (2019). The ecosystem approach to aquaculture 10 years on-a critical review and consideration of its future role in blue growth. Reviews in Aquaculture, 11(3), 493-514.

Buck, B. H., \& Langan, R. (2017). Aquaculture Perspective of Multi-Use Sites in the Open Ocean: The Untapped Potential for Marine Resources in the Anthropocene. Springer Nature.

Caswell, B. A., Klein, E. S., Alleway, H. K., Ball, J. E., Botero, J., Cardinale, M., Eero, M., Engelhard, G. H., Fortibuoni, T., \& Giraldo, A. J. (2020). Something old, something new: Historical perspectives provide lessons for blue growth agendas. Fish and Fisheries, 21(4), 774-796. 
Chow, W. S., \& Chen, Y. (2012). Corporate sustainable development: Testing a new scale based on the mainland Chinese context. Journal of business ethics, 105(4), 519-533.

Chu, S. H., Yang, H., Lee, M., \& Park, S. (2017). The impact of institutional pressures on green supply chain management and firm performance: Top management roles and social capital. Sustainability, 9(5), 764.

Cochran, W. G. (2007). Sampling techniques (3rd ed.). John Wiley \& Sons.

Creswell, J. W., \& Creswell, J. D. (2017). Research design: Qualitative, quantitative, and mixed methods approaches (5th ed.). SAGE Publications.

Dalton, G., Bardócz, T., Blanch, M., Campbell, D., Johnson, K., Lawrence, G., Lilas, T., Friis-Madsen, E., Neumann, F., \& Nikitas, N. (2019). Feasibility of investment in Blue Growth multiple-use of space and multi-use platform projects; results of a novel assessment approach and case studies. Renewable and Sustainable Energy Reviews, 107, 338-359.

Daly, J., Knott, C., Keogh, P., \& Singh, G. G. (2021). Changing climates in a blue economy: Assessing the climate-responsiveness of Canadian fisheries and oceans policy. Marine Policy, 131, 104623.

Eikeset, A. M., Mazzarella, A. B., Davíðsdóttir, B., Klinger, D. H., Levin, S. A., Rovenskaya, E., \& Stenseth, N. C. (2018). What is blue growth? The semantics of "Sustainable Development" of marine environments. Marine Policy, 87, 177-179.

FAO. (2015). (Fisheries and Aquaculture non serial publications, Issue. FAO.

Froehlich, H. E., Afflerbach, J. C., Frazier, M., \& Halpern, B. S. (2019). Blue growth potential to mitigate climate change through seaweed offsetting. Current Biology, 29(18), 3087-3093. e3083.

Geisser, S. (1975). The predictive sample reuse method with applications. Journal of the American statistical Association, 70(350), 320-328.

Grinyer, J., Russell, A., \& Collison, D. (1998). Evidence of managerial short-termism in the UK. British Journal of Management, 9(1), 13-22. 
Guijarro-García, M., Carrilero-Castillo, A., \& Gallego-Nicholls, J. F. (2020). Blue Ocean Strategy as a Framework for Business Innovation in China and Spain: A Summative Content Analysis of Innovation Initiatives and Value Propositions. In Analyzing the Relationship Between Innovation, Value Creation, and Entrepreneurship (pp. 146-181). IGI Global.

Hair, J. F., Hollingsworth, C. L., Randolph, A. B., \& Chong, A. Y. L. (2017). An updated and expanded assessment of PLS-SEM in information systems research. Industrial Management \& Data Systems, 117(3), 442-458.

Hair, J. F., Hult, G. T. M., Ringle, C., \& Sarstedt, M. (2016). A primer on partial least squares structural equation modeling (PLS-SEM) (2nd ed.). Sage Publications.

Hair, J. F., Ringle, C. M., \& Sarstedt, M. (2011). PLS-SEM: Indeed a silver bullet. Journal of Marketing theory and Practice, 19(2), 139-152.

Hair, J. F., Ringle, C. M., \& Sarstedt, M. (2013). Partial least squares structural equation modeling: Rigorous applications, better results and higher acceptance. Long Range Planning, 46(1-2), 1-12.

Hair, J. F., Risher, J. J., Sarstedt, M., \& Ringle, C. M. (2019). When to use and how to report the results of PLS-SEM. European Business Review, 31(1), 2-24.

Henseler, J., Ringle, C. M., \& Sarstedt, M. (2015). A new criterion for assessing discriminant validity in variance-based structural equation modeling. Journal of the academy of marketing science, 43(1), 115-135.

Hossain, M., Alamgir, M., Uddin, S., \& Chowdhury, M. (2020). Seaweeds for Blue Economy in Bangladesh. Food and Agriculture Organization of the United Nations.

Humayun, A., \& Zafar, N. (2014). Pakistan's 'Blue Economy': Potential and Prospects. Policy Perspectives: The Journal of the Institute of Policy Studies, 11(1), 57-76.

Hussain, M. G., Failler, P., Al Karim, A., \& Alam, M. K. (2017). Review on opportunities, constraints and challenges of blue economy development in Bangladesh. Journal of Fisheries and Life Sciences, 2(1), 45-57. 
Jouffray, J.-B., Blasiak, R., Norström, A. V., Österblom, H., \& Nyström, M. (2020). The blue acceleration: the trajectory of human expansion into the ocean. One Earth, 2(1), 43-54.

Jung, J. M., \& Kellaris, J. J. (2004). Cross-national differences in proneness to scarcity effects: The moderating roles of familiarity, uncertainty avoidance, and need for cognitive closure. Psychology \& Marketing, 21(9), 739-753.

Kamalia, U. H. I. (2020). The influence of uncertainty avoidance and future orientation

Katila, J., Ala-Rämi, K., Repka, S., Rendon, E., \& Törrönen, J. (2019). Defining and quantifying the sea-based economy to support regional blue growth strategiescase Gulf of Bothnia. Marine Policy, 100, 215-225.

Khan, M. Z. (2020). Strategic Human Resource Development: Investing in Balochistan's Blue Economy. Strategic Studies, 40(1).

Klinger, D. H., Eikeset, A. M., Davíðsdóttir, B., Winter, A.-M., \& Watson, J. R. (2018). The mechanics of blue growth: management of oceanic natural resource use with multiple, interacting sectors. Marine Policy, 87, 356-362.

KOCA, S., \& SAĞSAN, M. (2020). The Mediating Role of Organizational Innovation in the Implementation of Intellectual Capital and Blue Ocean Strategy for Higher Education Sustainability. Revista Argentina de Clínica Psicológica, 29(5), 15521566.

Kyvelou, S. S. I., \& Ierapetritis, D. G. (2019). How to make blue growth operational? A local and regional stakeholders perspective in Greece. WMU Journal of Maritime Affairs, 18(2), 249-280.

Lagasco, F., Collu, M., Mariotti, A., Safier, E., Arena, F., Atack, T., Brizzi, G., Tett, P., Santoro, A., \& Bourdier, S. (2019). New engineering approach for the development and demonstration of a multi-purpose platform for the blue growth economy. International Conference on Offshore Mechanics and Arctic Engineering,

Leposa, N. (2020). Problematic blue growth: A thematic synthesis of social sustainability problems related to growth in the marine and coastal tourism. Sustainability Science, 15(4), 1233-1244. 
Lin, W.-C., \& Cheng, H.-H. (2020). Improving maritime safety through enhancing marine process management: the application of balanced scorecard. Management Decision.

Lopes, I., Nogueira, N., Canning Clode, J., \& Sepúlveda, P. (2019). Finding the balance of Blue Growth sustainable development within Ecosystem approach: Analysis of Maritime Transport in Macaronesia under MSFD.

Malbašić, I., Rey, C., \& Potočan, V. (2015). Balanced organizational values: From theory to practice. Journal of business ethics, 130(2), 437-446.

Marston, C. L., \& Craven, B. M. (1998). A survey of corporate perceptions of shorttermism among analysts and fund managers. The European Journal of Finance, 4(3), 233-256.

Mayén Cañavate, B., Bernal Conesa, J. A., Briones Peñalver, A. J., \& Anunciação, P. (2019). Tourism in the Blue Growth strategy: a model proposal. Anatolia, 30(2), 267-278.

Muñoz-van den Eynde, A., Cornejo-Cañamares, M., Diaz-Garcia, I., \& Muñoz, E. (2015). Measuring innovation culture: development and validation of a multidimensional questionnaire. Advances in Research, 122-141.

Newman, I., \& Benz, C. R. (1998). Qualitative-quantitative research methodology: Exploring the interactive continuum. SIU Press.

Nunnally, J. C., \& Bernstein, I. H. (1994). Psychometric Theory (3rd ed.). McGraw-Hill Education.

Pauli, G. A. (2010). The blue economy: 10 years, 100 innovations, 100 million jobs. Paradigm publications.

Ramakrishnan, K. (2010). The competitive response of small, independent retailers to organized retail: Study in an emerging economy. Journal of Retailing and Consumer Services, 17(4), 251-258.

Recalde, M. E. Q. (2019). Innovation and blue growth in the Atlantic sea basin: a bibliometric analysis. 
Reinertsen, H., \& Asdal, K. (2019). Calculating the blue economy: producing trust in numbers with business tools and reflexive objectivity. Journal of Cultural Economy, 12(6), 552-570.

Sadiq, S., Amjad, M. S., Rafique, M. Z., Hussain, S., Yasmeen, U., \& Khan, M. A. (2021). An integrated framework for lean manufacturing in relation with blue ocean manufacturing-a case study. Journal of Cleaner Production, 279, 123790.

Saviolidis, N. M., Davíðsdóttir, B., Ilmola, L., Stepanova, A., Valman, M., \& Rovenskaya, E. (2020). Realising blue growth in the fishing industry in Iceland and Norway: Industry perceptions on drivers and barriers to blue growth investments and policy implications. Marine Policy, 117, 103967.

Schultz-Zehden, A., Weig, B., \& Lukic, I. (2019). Maritime Spatial Planning and the EU's Blue Growth Policy: Past, present and future perspectives. In Maritime Spatial Planning (pp. 121-149). Palgrave Macmillan, Cham.

Scott, G., \& Garner, R. (2013). Doing qualitative research: designs, methods, and techniques (1st ed.). Pearson

Segelod, E. (2000). A comparison of managers' perceptions of short-termism in Sweden and the US. International Journal of Production Economics, 63(3), 243-254.

Sekaran, U., \& Bougie, R. (2010). Research for Business-A Skill Building Approach (5th ed.). John-Wiley and Sons.

Sekaran, U., \& Bougie, R. (2016). Research methods for managers: a skill-building approach (7th ed.). John Wiley \& Sons, Inc.

Stone, M. (1974). Cross-validatory choice and assessment of statistical predictions. Journal of the royal statistical society. Series B (Methodological), 36(2), 111-147.

Van den Burg, S. W., Aguilar-Manjarrez, J., Jenness, J., \& Torrie, M. (2019). Assessment of the geographical potential for co-use of marine space, based on operational boundaries for Blue Growth sectors. Marine Policy, 100, 43-57.

Vehovar, V., Toepoel, V., \& Steinmetz, S. (2016). Non-probability sampling. In The Sage handbook of survey methods (pp. 329-345). Sage. 
Wenhai, L., Cusack, C., Baker, M., Tao, W., Mingbao, C., Paige, K., Xiaofan, Z., Levin, L., Escobar, E., \& Amon, D. (2019). Successful blue economy examples with an emphasis on international perspectives. Frontiers in Marine Science, 6, 261.

Yıldız, S., Baştürk, F., \& Boz, İ. T. (2014). The effect of leadership and innovativeness on business performance. Procedia-Social and Behavioral Sciences, 150, 785793.

Zafar, N. (2021). Building Maritime Security in Pakistan-The Navy Vanguard. In Capacity Building for Maritime Security (pp. 73-96). Springer. 